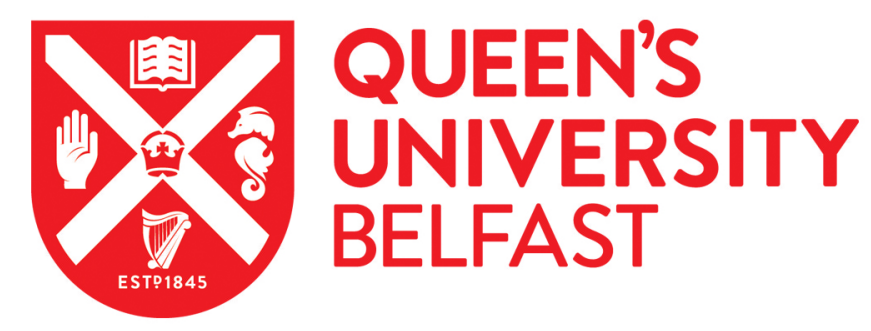

\title{
FSS Design and Manufacturing Challenges for Future Space Science Missions
}

Dickie, R., Cahill, R., Baine, P., \& Fusco, V. (2018). FSS Design and Manufacturing Challenges for Future Space Science Missions. In Proceedings of the 12th European Conference on Antennas and Propagation $(E U C A P)$ Institute of Electrical and Electronics Engineers Inc..

\section{Published in:}

Proceedings of the 12th European Conference on Antennas and Propagation (EuCAP)

\section{Document Version:}

Peer reviewed version

\section{Queen's University Belfast - Research Portal:}

Link to publication record in Queen's University Belfast Research Portal

\section{Publisher rights}

(c) 2017 IEEE. This work is made available online in accordance with the publisher's policies. Please refer to any applicable terms of use of the publisher.

\section{General rights}

Copyright for the publications made accessible via the Queen's University Belfast Research Portal is retained by the author(s) and / or other copyright owners and it is a condition of accessing these publications that users recognise and abide by the legal requirements associated with these rights.

Take down policy

The Research Portal is Queen's institutional repository that provides access to Queen's research output. Every effort has been made to ensure that content in the Research Portal does not infringe any person's rights, or applicable UK laws. If you discover content in the Research Portal that you believe breaches copyright or violates any law, please contact openaccess@qub.ac.uk. 


\title{
FSS Design and Manufacturing Challenges for Future Space Science Missions
}

\author{
R. Dickie ${ }^{1}$, R.Cahill ${ }^{1}$, P. Baine ${ }^{2}$, V.F. Fusco ${ }^{1}$ \\ ${ }^{1}$ The Institute of Electronics, Communications and Information Technology (ECIT), Queen's University Belfast, Northern \\ Ireland Science Park, Queen's Road, Queen's Island, Belfast BT3 9DT, Northern Ireland, UK, r.dickie@qub.ac.uk \\ ${ }^{2}$ Queen's Advanced Micro Engineering Centre, School of Electronics, Electrical Engineering and Computer Science, Ashby \\ Building, Stranmillis Road, Belfast, BT9 5AH
}

\begin{abstract}
The purpose of this paper is to provide an overview of the innovative design and manufacturing strategies that have led to the creation of a new class of freestanding Frequency Selective Surface (FSS) with unrivalled electromagnetic, thermal and structural performances. These structures, when deployed as free space electromagnetic filters, provide passive remote sensing instruments with multispectral capability by separating the scene radiation into separate frequency channels. Ultra-low loss spatial beam splitting enables high sensitivity receivers to detect weak molecular emissions at $\mathrm{mm}$ to sub-mm wavelengths, independent of the polarisation and angular direction of the propagating waves. This new generation of FSS is shown to satisfy the technically challenging performance and functionality that is required for next generation Earth observation radiometers. Moreover, building on this work we present a new concept for creating electronically tunable quasi optical switches based on a reconfigurable FSS structure that is suitable for deployment in future radiometer calibration arrangements.
\end{abstract}

Index Terms - atmospheric science instrumentation, frequency selective surface, FSS, mm-wave, reconfigurable

\section{INTRODUCTION}

OVER the past decade major advances have been made in space borne mm-wave instrument technology, primarily to address the need to study the processes driving the climate and to monitor the changes to the environment [1]. The process requires complex imaging of clouds [2] and spectroscopic characterisation of carbon dioxide and other greenhouse gases in the Earth's atmosphere using remote sensing instruments. These operate over wide bandwidths covering the thermal emission lines of the gases being observed. To satisfy satellite payload constraints on cost, mass and energy consumption, passive Earth observation radiometers traditionally employ a single mechanically scanned aperture antenna to collect the radiation. FSS demultiplexing elements are a key enabling technology for these advanced instruments and are used in the quasi-optical receiver to spectrally separate the signals that are collected by the scanning antenna [3]. These FSS operate at $45^{\circ}$ incidence and exhibit very high mechanical strength and suitable CTE properties. They must also exhibit very low signal band insertion loss and simultaneously meet the conflicting requirement for high isolation between adjacent frequency bands. This is required to minimize the overall noise performance of the instrument and thereby achieve high receiver sensitivity which is necessary to detect weak molecular emissions. In addition the FSS must also exhibit high performance at large incident angles to reduce the footprint of the feed train and moreover the structure should be sufficiently robust to withstand the launch forces of the space vehicle and operate without failure in the harsh thermal environment. This paper describes some of the main innovative electromagnetic design strategies - including reconfigurable FSS, precision micromachining technology and measurement techniques that have been employed to create a new class of ultra-low loss freestanding quasi-optical filters which can simultaneously separate vertical and horizontal polarized components of naturally occurring thermal emissions with spectral efficiencies up to $93 \%$ at frequencies up to $700 \mathrm{GHz}$.

\section{FSS DESIGN}

Passive remote sensing of the atmosphere from space provides a wide range of information, including the size and shape of water ice particles in cirrus clouds and the abundance of molecular species. FSS structures are normally employed in passive remote sensing radiometers to separate signals with electric vectors that are either orientated parallel (TM) or perpendicular (TE) to the plane of incidence. However for some recently planned missions the functionality of these filters must be increased to facilitate the detection and analysis of dual polarized radiation. An FSS operating at $664 \mathrm{GHz}$ which provides this demanding requirement is shown in Fig. 1. This FSS separates the passband from four lower frequency reflection bands in both the TE and TM planes when orientated at $45^{\circ}$ incidence in the radiometer. The specified maximum signal loss in the transmission and reflection bands is $0.5 \mathrm{~dB}$ 
and for its intended application (Microwave Imager Instruments (MWI) for cloud ice particle analysis) the frequency separation ratio of the FSS is 1.44:1 $(657.3 / 456.7 \mathrm{GHz})$, therefore a single freestanding screen can satisfy these requirements. The FSS geometry and dimensions are based on a Jerusalem cross unit cell. Coincident spectral responses are obtained by adjusting the individual lengths of the vertical and horizontal main arms and increasing the physical width of the latter to remove passband narrowing which is observed when the structure is excited by a TE polarized wave at oblique incidence.

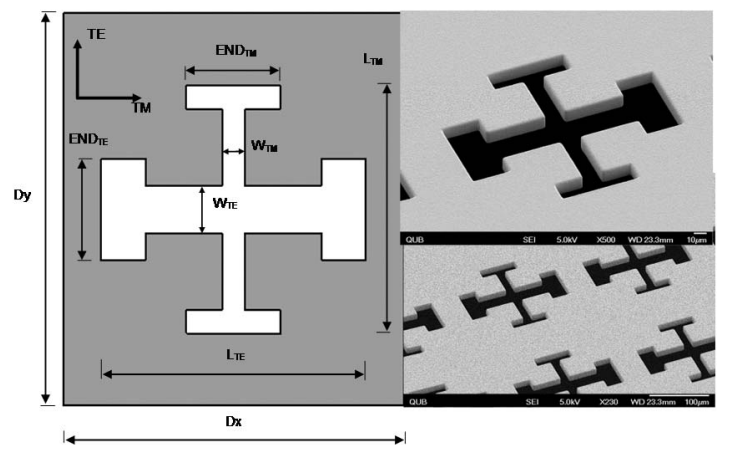

Fig. 1. Geometry and dimensions $(\mu \mathrm{m})$ of unit cell, and scanning electron micrographs of MWI $664 \mathrm{GHz}$ FSS [4]

$\mathrm{L}_{\mathrm{TM}}=158, \mathrm{~L}_{\mathrm{TE}}=179, \mathrm{~W}_{\mathrm{TM}}=15, \mathrm{~W}_{\mathrm{TE}}=30, \mathrm{END}_{\mathrm{TM}}=64$, $\mathrm{END}_{\mathrm{TE}}=65, \mathrm{Dx}=230, \mathrm{Dy}=250$

Moreover the capacitive loading introduced by the end caps of the Jerusalem Cross elements reduces the area occupied by the slot in each unit cell and this increases the structural integrity of the filter. The predicted and measured results are depicted in Fig. 2 where it is shown that the maximum loss in the transmission and reflection band is below $0.5 \mathrm{~dB}$ in both planes of polarization.

The design of a polarization independent FSS is significantly more complicated when the transmission and reflection bands are very closely spaced. Suitable topologies that can be employed to create a FSS which separates the signal 316.5 $325.5 \mathrm{GHz}$ and image $349.5-358.5 \mathrm{GHz}$ channels of the MARSCHALS [5] radiometer have been studied. Fig. 3 shows a two layer arrangement which consists of two nested short circuited rectangular loop slots and a rectangular dipole slot. Reference [6] describes the systematic design approach which was employed to achieve the desired filter performance, namely to provide spatial demultiplexing of two channels with a frequency separation ratio of 1.07:1. At the specified centre operating frequency $321 \mathrm{GHz}$ the length of the inner slot is $\approx \lambda / 2$ and the outer slot length is $\approx \lambda$. Therefore when these are excited by TM and TE polarized waves respectively, the structure resonates at the same frequency and the orthogonally orientated signals transmit through the FSS, without incurring significant losses.

(Fig. 2 inset)

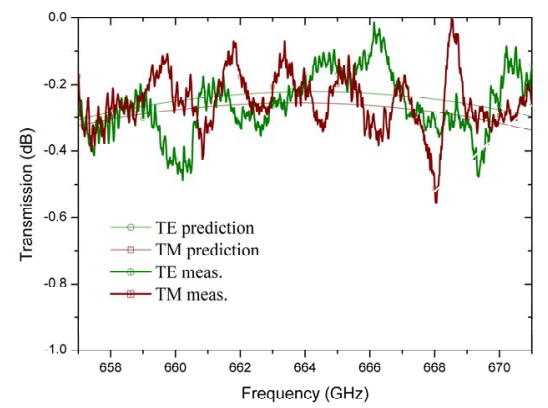

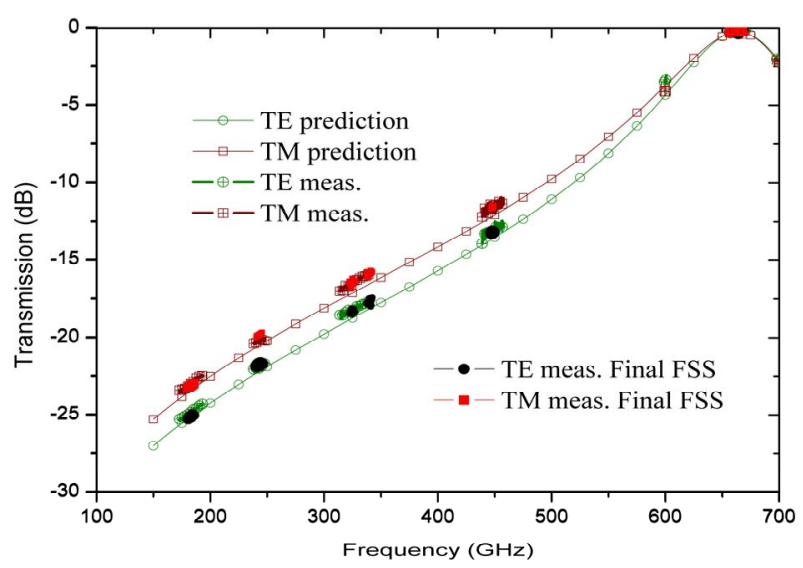

Fig. 2. Computed and measured spectral responses of the MWI $664 \mathrm{GHz}$ dual polarization FSS, with passband inset - the plot also shows the measured response of a second technology demonstrator 'Final FSS', used to confirm manufacturing repeatability[4]

The magnetic current distribution at resonance in the TM plane (inner slot) and the TE plane (outer slot) and a scanning electron micrograph image of three unit cells of the assembled and bonded two layer FSS are depicted in Fig. 3. The computed and experimental results plotted in Fig. 4 show that the structure exhibits a maximum insertion loss of $0.6 \mathrm{~dB}$ (316.5 $325.5 \mathrm{GHz}),>30 \mathrm{~dB}$ rejection $(349.5-358.5 \mathrm{GHz})$ and crosspolar levels below $-25 \mathrm{~dB}$ simultaneously for TE and TM polarisations at $45^{\circ}$ incidence.

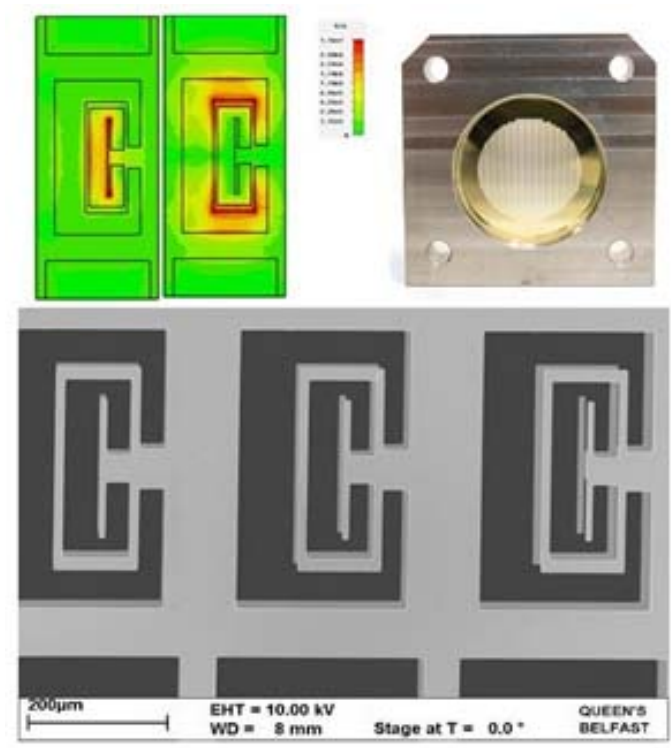

Fig. 3. Computed electric field distribution, SEM and photograph of the two layer dual polar FSS mounted in an invar holder [6] 


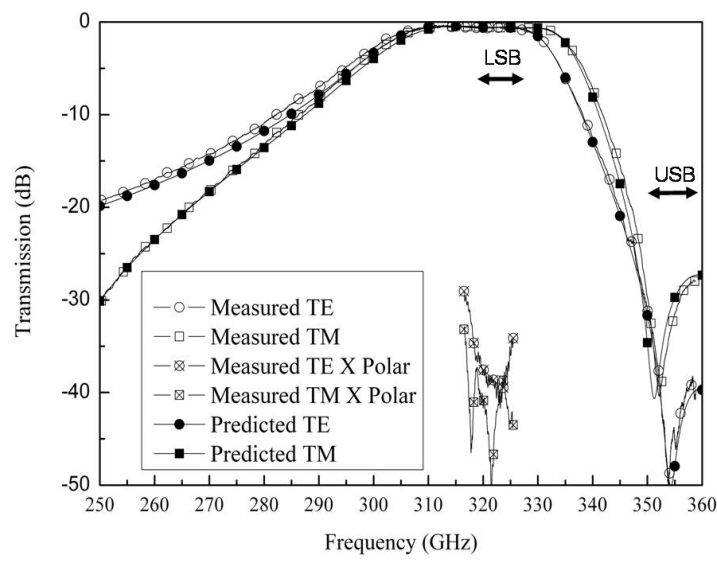

Fig. 4. Measured and computed spectral response of polarisation independent FSS [6]

\section{FABRICATION AND SPACE QUALIFICATION}

For the two structures described it is essential to remove the dielectric loss component of the structure, because this is the only way that the demanding insertion loss requirements can be met at resonance. This is particularly important for the design of multilayer FSS screens since these exhibit multiple internal reflections that result in a large effective path length through the lossy dielectric spacer. The preferred manufacturing route for creating substrateless FSS is to form the individual perforated screens by high conductivity coatings on silicon wafers. Single crystal silicon was chosen as the base material of the structure because it has very high theoretical yield strength, typically $7000 \mathrm{MPa}$, and therefore provides a very rigid core with desirable structural properties. The FSS shown in Fig 1 and 3 are constructed from $100 \mathrm{~mm}$ diameter silicon on insulator (SOI) material which consists of a handle silicon wafer (typically $400 \mu \mathrm{m}$ thick) with a $3 \mu \mathrm{m}$ buried oxide insulating layer on top of which is a $10 \mu \mathrm{m}$ active silicon surface. The SOI wafers are coated with photo resist and patterned to form a mask for the Deep Reactive Ion Etching (DRIE) process which etches the $10 \mu \mathrm{m}$ silicon layer at a rate of $3.5 \mu \mathrm{m} /$ minute. DRIE is also used to remove the exposed silicon under the array and release rings. Removal of the buried silicon dioxide layer creates a $50 \mathrm{~mm}$ diameter freestanding structure containing the $30 \mathrm{~mm}$ diameter perforated FSS and a $10 \mathrm{~mm}$ wide silicon annulus with the same thickness as the handle wafer. Fig. 5 summarizes the main process steps.

The FSS are then sputter coated with a titanium adhesion layer followed by a $0.25 \mu \mathrm{m}$ thick copper seed layer. The construction is completed by growing a $1 \mu \mathrm{m}$ thick electrodeposited silver coating on the seed layer and applying a $25 \mathrm{~nm}$ thick layer of gold to prevent oxidation. For multilayer FSS (Fig. 3) the spacer separation between screens is created by placing epoxy binder containing glass spheres around the annulus of one screen. The measured dimensional tolerances of the slot elements is within $\pm 2 \mu \mathrm{m}$ and the separation distance is within $\pm 5 \mu \mathrm{m}$ of the nominal design value (e.g. $200 \mu \mathrm{m}-$ Fig. 3 ) for the multilayer arrangements. The construction technique was selected to satisfy the structural and thermal demands of the space environment. This approach exploits the high mechanical strength and rigidity of silicon. Detailed mechanical analysis has been carried out by Airbus Space and Defence in the UK to quantify the dynamic behaviour and peak stress levels of the structure shown in Fig. 3.

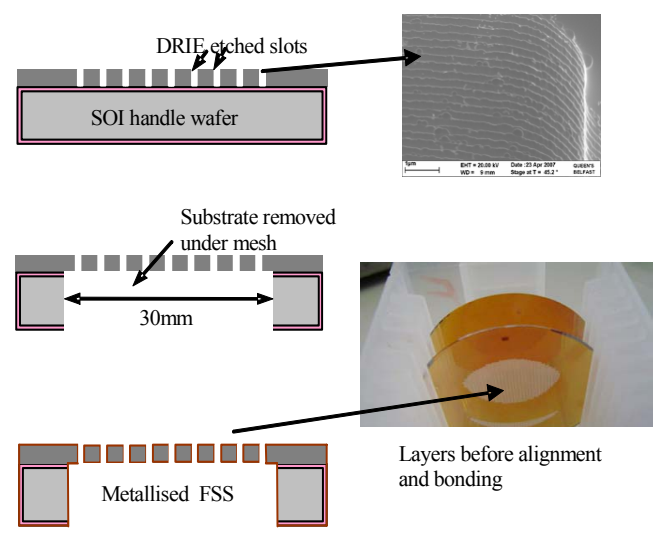

Fig. 5. Key processing steps used to construct FSS

The predicted natural frequency obtained from a finite element model of the $30 \mathrm{~mm}$ diameter structure is $148 \mathrm{GHz}$ and therefore meets the minimum requirement with $48 \%$ margin. Fig. 6 shows a FEM model of the freestanding FSS and a single unit cell containing 50,000 elements.
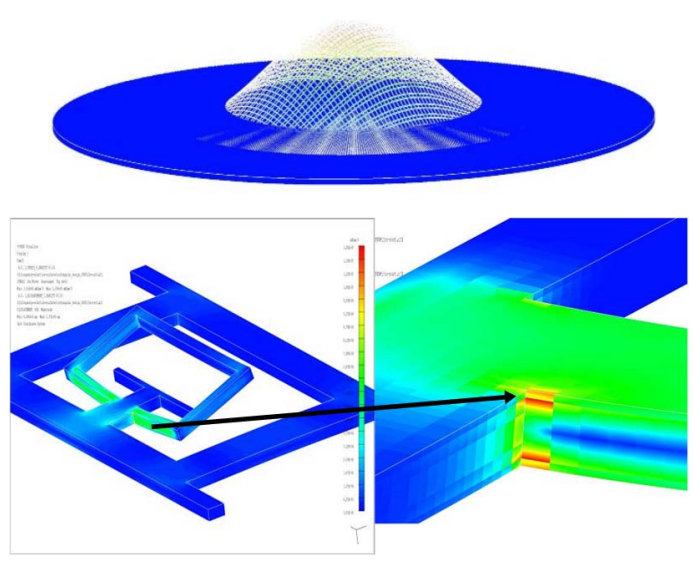

Fig. 6. FEM structural analysis showing the natural frequency and stress concentrations of the dual polarisation FSS

These were used to model the stress contours during random vibration and the stress concentrations, which are shown above. The highest stress levels predicted in the silicon was $487 \mathrm{MPa}$ which is more than ten times lower than the allowable yield (7000 MPa). Random and sine vibration testing in three axes was performed to space qualification levels at the Airbus Portsmouth environmental test facility [7]. In addition thermal 
cycling was used to demonstrate that the FSS can survive in orbit temperatures. Five cycles between $\quad-20^{\circ} \mathrm{C}$ and $+60^{\circ} \mathrm{C}$ with a dwell time of 1 hour was used to test the filter. Visual inspection before and after testing confirmed the robustness of the FSS and pre and post-test spectral measurements showed no degradation in the spectral performance of the filter.

\section{FUTURE DIRECTION - RECONFIGURABLE FSS}

The development of a reconfigurable FSS using freestanding technology offers the benefits of low insertion loss combined with a tunable bandpass response. In operation, the method uses the proximity of a thin layer of high permittivity dielectric material and a periodic slot FSS. The FSS comprises a freestanding mesh of strongly shaped slot elements as described in the previous section, while the dielectric layer is a thin diaphragm $\sim 10-30 \mu \mathrm{m}$ thickness that couples strongly with the electric fields that are produced in the slots at resonance. The actuation method uses piezo actuators to translate the dielectric layer in front of the FSS's metal surface, this is shown in Fig. 7(a).

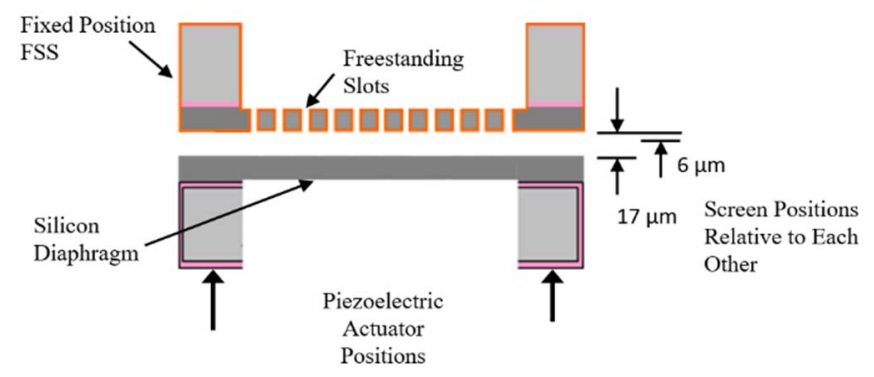

(a)

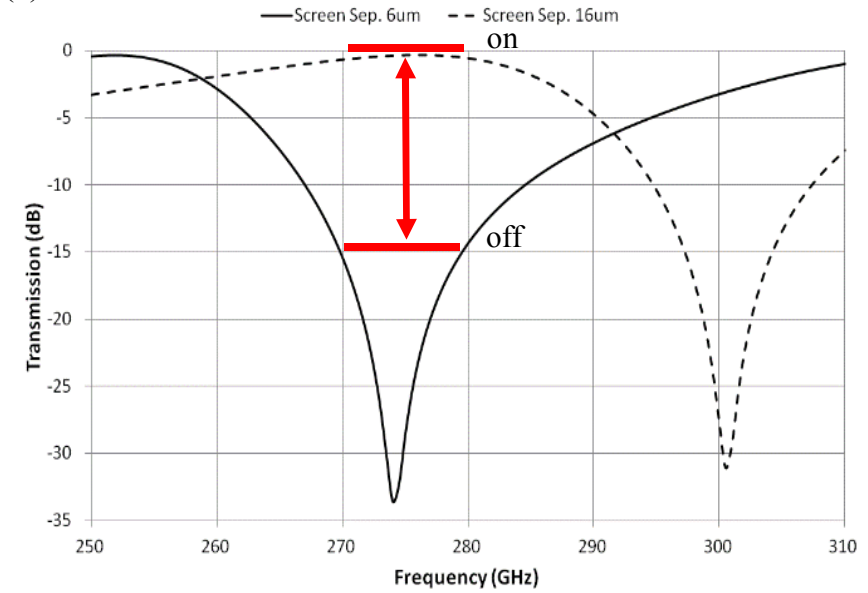

(b)

Fig. 7 (a) Sectional view of the reconfigurable FSS, (b) simulated response of the FSS, showing the stopband at 300 $\mathrm{GHz}$ reconfigured to $274 \mathrm{GHz}$

When the air gap between the two layers is increased this shifts the FSS transmission resonance higher in frequency. Using a high permittivity material such as silicon $\left(\varepsilon_{\mathrm{r}}=11.9\right)$ gives a significant amount of frequency change when the layer is translated within the range of the piezoelectric actuator $(0$ $20 \mu \mathrm{m})$. As the dielectric layer moves away from the FSS the resonant frequency returns to the freestanding case. The silicon diaphragm layer when translated by $6-16 \mu \mathrm{m}$ from the mesh surface produces a $26 \mathrm{GHz}$ frequency shift of the passband which is centred around $275 \mathrm{GHz}$, this is depicted in Fig. 7(b). It also shows that the arrangement provides dynamic switching between 'on' and 'off' states with $0.3-0.65 \mathrm{~dB}$ insertion loss, and high isolation of over $15 \mathrm{~dB}$ between $270-$ $280 \mathrm{GHz}$. The physical movement between the two screens can be precisely controlled by the piezoelectric actuators positioned at the edges of the device.

\section{CONCLUSIONS}

This paper briefly described many of the innovative design techniques and manufacturing processes that have led to the creation of state of the art FSS filters operating at $\mathrm{mm}$ to sub$\mathrm{mm}$ wave wavelengths. The technology has mainly been driven by the need to satisfy the stringent electrical and mechanical performance specifications for separating signals in advanced Earth observation instruments. The manufacturing process developed at QUB is wholly compatible with the structural and thermal requirements for space hardware. Following on from these developments first results for a new reconfigurable FSS using piezoelectric actuators has been presented. The device which can be used to provide high frequency dynamic switching, exhibits low insertion loss and high isolation at the working frequency of $275 \mathrm{GHz}$. The next stage of the work will be to manufacture and test the device.

\section{REFERENCES}

[1] C. Mangenot, "Space antennas: ESA's perspectives on future needs and technologies," presented at the 13th Int. Symp. on Antennas, France, 2004.

[2] V. Kangas, C. Lin and M. Betto, "Microwave Instrument Requirements and Technology Needs for the Post-EPS Mission," Proc 31st ESTEC Antenna Workshop on Millimetre and sub-millimetre waves - From technologies to systems, The Netherlands, May 2009. European Space Agency, pp. 501 -506.

[3] R. J. Martin and D. H. Martin, "Quasi-optical antennas for radiometric remote sensing," Electron. Comm. Eng. J., vol. 8, pp. 37-48, Feb. 1996.

[4] R. Dickie, R. Cahill, V. F. Fusco, H. S. Gamble, Y. Munro, S. Rea, "Recent advances in submillimetre wave FSS technology for passive remote sensing instruments," Proc. $4^{\text {rd }}$ European Conference on Antennas and Propagation, EuCAP, Barcelona, April 2010.

[5] M. Oldfield, B. Moyna, E. Allouis , R. Brunt, U. Cortesi, B. Ellison, J. Ellison, J. Eskell, T. Forward, T. Jones, D. Lamarre, J. Langen, P. de Maagt, D. Matheson, I. Morgan, J. Reburn, and R. Siddan, "MARSCHALS: Development of an airborne millimetre-wave limb sounder," in Proc. 8th Int. Symp. on Remote Sensing, SPIE, Sept. 2001, vol. 4540, pp. 221-228.

[6] R. Dickie, R. Cahill, H. S. Gamble, V. F. Fusco, M. Henry, M. L. Oldfield, P. G. Huggard, P. Howard, N. Grant, Y. Munro, and P. de Maagt, "Submillimetre wave frequency selective surface with polarisation independent spectral responses," Proc IEEE Antennas and Propagation, vol. 57, pp. 1985 - 1994, July 2009.

[7] Tests conducted in Airbus Defence \& Space Laboratories in Portsmouth, http://www.airbus.com 